\title{
A FILOSOFIA DE MACHADO DE ASSIS
}

Artigo originalmente publicado no Diário de Notícias do Rio de Janeiro, em 22 de dezembro de 1940, p. 17-20.

\section{SÉRGIO BUARQUE DE HOLANDA}

Universidade de São Paulo

São Paulo, SP, Brasil

APRESENTAÇÃO DE MARCELO DIEGO

Universidade Federal do Rio de Janeiro

Rio de Janeiro, Rio de Janeiro, Brasil

Resumo: Em dezembro de 1940, em sua coluna literária no jornal Diário de Notícias, do Rio de Janeiro, o crítico literário, historiador e jornalista Sérgio Buarque de Holanda publica artigo em que questiona os argumentos do recémlançado livro de Afrânio Coutinho, A filosofia de Machado de Assis. No centro da polêmica está o grau de importância que cada um dos dois analistas atribui à recepção dos escritos de Pascal na obra machadiana: enquanto Coutinho defende o jansenismo como principal fonte da "filosofia de Machado de Assis", Holanda propõe o ceticismo como a atitude que melhor caracterizaria o pensamento do escritor brasileiro.

Palavras-chave: Diário de Notícias; Afrânio Coutinho; Pascal; jansenismo; ceticismo.

\section{THE PHILOSOPHY OF MACHADO DE ASSIS}

\begin{abstract}
In December of 1940, in Sérgio Buarque de Holanda's column in newspaper Diário de Notícias, the literary critic, historian and journalist published an article in which he questions the arguments contained in the then-recently launched book, A filosofia de Machado de Assis, by Afrânio Coutinho. At the center of the controversy is the degree of importance either of the annalists attributes to the reception of Pascal's writing in the work of Machado de Assis: while Coutinho defends Jansenism as the main source for "the philosophy of Machado de Assis", Holanda proposes skepticism as the attitude that better characterizes the Brazilian writer's thinking.
\end{abstract}

Keywords: Diário de Notícias; Afrânio Coutinho; Pascal; Jansenism; skepticism. 
Desde cedo, Sérgio Buarque de Holanda (São Paulo, 1902-1982) demonstrou interesse pela literatura e pelas artes, tendo sido confiada a ele por Mário de Andrade e Oswald de Andrade, em 1922, quando tinha apenas vinte anos idade - a tarefa de representar a revista Klaxon no Rio de Janeiro. Também desde cedo o bacharel em Direito, jornalista e historiador (que publicara em 1936 o ensaio Raízes do Brasil, número inaugural da coleção "Documentos brasileiros", da Editora José Olympio, dirigida por Gilberto Freyre) se exercitou na crítica literária, porém foi em 1940, quando assumiu, por indicação de Mário de Andrade, a coluna literária do Diário de Notícias, jornal de maior circulação do Rio de Janeiro à época, que começou a praticála de forma sistemática.

Em 22 de dezembro de 1940, Holanda dedicou o espaço de sua coluna à apreciação do livro A filosofia de Machado de Assis, de Afrânio Coutinho (Salvador, 1911-2000, Rio de Janeiro), publicado naquele mesmo ano, ainda na esteira das celebrações do centenário de nascimento do autor de Dom Casmurro, em 1939. Se já chama a atenção a relativa juventude do crítico, que aos 38 anos desempenhava esse papel de autoridade, chama ainda mais a atenção a juventude do criticado, que aos 29 anos se dispunha a distinguir e examinar as matrizes de pensamento na obra de Machado de Assis. Cabe notar, entretanto, que em 1940 Holanda já havia passado por momentos decisivos da sua formação e trajetória intelectual (como a estada na Alemanha, a experiência da docência universitária e a publicação de Raízes do Brasil), ao passo que Coutinho ainda não os experienciara (seu período de estudos nos Estados Unidos teria início em 1942, e a sua entrada no ensino superior, em 1950).

A despeito do tom - por falta de melhor palavra - cordial, respeitoso e elegante como de costume, o artigo é essencialmente crítico em relação ao livro. Para Holanda, Coutinho peca ao atribuir excessiva importância à ascendência do pensamento de Pascal sobre a filosofia de Machado de Assis e ao não fazer distinção entre esse pensamento e a doutrina jansenista. Sua crítica, portanto, não tem como objeto um equívoco, senão um exagero e uma imprecisão; Holanda não invalida, nem rejeita, a leitura que Coutinho faz da dimensão filosófica na obra machadiana, mas antes lhe cobra perspectiva e rigor. Provocado pela de Coutinho, Holanda expõe a sua própria leitura de Machado de Assis, tema a que apenas tangencialmente retornará, em sua prolífica escrita como crítico e historiador. ${ }^{1}$ Dessa leitura, sublinhe-se a

${ }^{1}$ Sobre esse assunto, cf. Monteiro (2018). 
proposição do ceticismo como corrente filosófica de amplo impacto sobre a literatura machadiana, e o destaque dado ao humour nessa literatura.

Em 1944, Holanda publicou a coletânea de artigos críticos Cobra de vidro, incorporando a ela o texto de "A filosofia de Machado de Assis", ligeiramente modificado; e em 1978 lançou uma segunda edição do mesmo livro, com mais algumas alterações no texto do artigo. Há, desse modo, três lições textuais do artigo. Embora a crítica textual recomende que se prefira, sempre, a última lição aprovada pelo autor em vida, a Machado de Assis em linha optou, excepcionalmente, pela primeira, por ser aquela que contém mais dados sobre a relação do texto com as suas condições específicas de produção e de recepção, tendo o cuidado de fornecer as variantes das lições seguintes em nota de rodapé.

Com a publicação de "A filosofia de Machado de Assis", de Sérgio Buarque de Holanda, a Machado de Assis em linha faz uma homenagem a esse discreto, porém agudo, crítico machadiano, ao mesmo tempo que convida os leitores a refletir sobre como essa peça crítica dialoga com a vasta obra do historiador, crítico literário e jornalista. A revista também deixa aqui registrado o seu agradecimento à família Buarque de Holanda, pela autorização dada para a publicação do artigo.

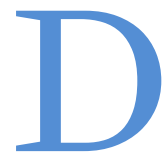

epois de tudo quanto se tem escrito nos últimos tempos acerca de Machado de Assis, sua personalidade ainda continua a oferecer estímulo para novas aventuras e descobrimentos. Nenhum outro autor brasileiro suportaria sem alguma perda de prestígio tal excesso de devoções póstumas. A ânsia de opiniões divergentes, o gosto das novidades, das controvérsias, das emulações, nesse caso, é um fenômeno singular em nossa vida literária, pois nada costuma satisfazer melhor os leitores, diante de um escritor glorioso, do que os juízos universais, compulsórios e bem disciplinados, capazes de proteger certo repouso da inteligência crítica.

Uma das explicações plausíveis para essa aura de popularidade é que só agora, passados mais de trinta anos de sua morte, a glória de Machado de Assis alcançou maturidade perfeita. A figura do escritor surge atualmente mais nítida, menos remota, do que há um ou dois decênios. É que se encerrou para ele essa espécie de hibernação que acompanha geralmente o 
desaparecimento de um grande espírito e que parece ser organicamente necessária, tal a constância com que se manifesta na história das literaturas.

O extraordinário nessa febre de entusiasmo que hoje envolve o nome de Machado de Assis não é apenas o número excessivo de estudos inspirados por sua vida e sua obra, mas o número de bons estudos, de interpretações felizes, de pesquisas laboriosas e honestas. Ao lado de trabalhos críticos ou crítico-biográficos como o da sra. Lúcia Miguel Pereira ou o do sr. Mário Matos, de biografias minuciosas como a do sr. Elói Pontes, de ensaios em profundidade como os do sr. Augusto Meyer, de investigações especializadas como as dos srs. Peregrino Júnior e Eugênio Gomes, ${ }^{2}$ surgiram excelentes documentários e homenagens, entre os quais merecem atenção o Catálogo da Exposição Machado de Assis, organizado pelo Instituto Nacional do Livro, e o número especial da Revista do Brasil consagrado à memória do romancista.

Em seguida a todas essas obras, que não obstante seu mérito desigual revelam um sincero empenho de compreensão e de análise, o sr. Afrânio Coutinho ainda consegue apresentar-nos um trabalho de pioneiro, ao publicar um volume sobre a filosofia de Machado de Assis (COUTINHO, 1940). Tal circunstância constituiu para mim a primeira surpresa proporcionada por seu livro, e devo confessar que a mais agradável. Conhecendo bem a coragem lúcida, a capacidade e a curiosidade intelectual que o autor tem mostrado em outros ensaios, iniciei sua leitura com um interesse profundamente simpático. $\mathrm{E}$ ainda receio que esse interesse não vá perturbar um pouco a ênfase com que julgo necessário frisar o que há de equívoco e forçado em sua tentativa de interpretação.

As concepções do mundo são numerosas como a humanidade e é natural que todo indivíduo as tenha, tão pessoais e inconfundíveis como o talho da letra ou o desenho da mão. Não é de estranhar, pois, que o romancista ofereça com sua obra de ficção uma filosofia, ainda quando não a exprima em forma sistemática ou coerente. Alguns chegam a explicar-nos sua visão do mundo - sua "mensagem", como se dizia aqui há dez anos $-^{3}$ fora de seus livros de ficção, e nesse caso a missão do crítico de ideias se torna incomparavelmente fácil. Quem procure apreender a filosofia de um D. H. Lawrence ou de um André Gide, por exemplo - para só falar em contemporâneos - não precisará recorrer aos seus romances.

\footnotetext{
${ }^{2}$ Na segunda edição (HOLANDA, 1978) de Cobra de vidro, não constam, ao longo de todo o artigo, os pronomes de tratamento (abreviados: "sr.", "sra.", "srs."), antes dos nomes dos contemporâneos do autor.

${ }^{3}$ Na primeira (HOLANDA, 1944) e na segunda (HOLANDA, 1978) edições de Cobra de vidro, não consta o trecho entre travessões, "- sua 'mensagem', como se dizia aqui há dez anos -".
} 
Machado de Assis não pertence a essa família. Sua obra, a menos didática que se possa imaginar, não propõe nenhum corpo de ideias muito preciso. O mais que com boa vontade se pode tirar de seus trabalhos críticos será um repertório de julgamentos estéticos, que não chegam sequer a compor um sistema. O sr. Tristão de Ataíde já mostrou efetivamente como é possível, colecionando as opiniões críticas expressas por Machado de Assis em diferentes estudos, extrair os elementos brutos de um código de bom gosto.

Por outro lado, certas ideias e sentimentos aparecem com tal insistência, tão à flor da pele através das obras do romancista, que se pode com algum exagero falar numa filosofia. Essa filosofia é o que constitui o objeto das preocupações do sr. Afrânio Coutinho em seu livro. Insinuando um estudo de literatura comparada, o autor começa por organizar uma classificação engenhosa e necessariamente um pouco arbitrária dos escritores que mais teriam sugestionado Machado de Assis. Distingue três categorias de influências: influências de concepção e técnica literária e de estilo; influências de humor; influências de filosofia ou concepção do mundo e do homem. Assinala também os livros prediletos de Machado, que seriam a Bíblia, o Prometeu, Hamlet e D. Quixote.

De tal classificação retém o autor, como é natural, o que chama as influências de filosofia ("Pascal e Montaigne, Schopenhauer, o Eclesiastes") e destas particularmente a de Pascal. Impressionado pela extensão ${ }^{4}$ dessa influência, o sr. Afrânio Coutinho ocupa quase todo o livro em fazer o confronto entre o mundo pascaliano e o de Machado de Assis. É esse o seu principal "descobrimento", embora a mesma aproximação já tenha sido feita de passagem pela sra. Lúcia Miguel Pereira. Todos os demais confrontos aparecem simplesmente como fundos de quadro, a tal ponto que o livro poderia intitular-se Pascal e Machado de Assis, sem que fosse preciso mudar uma só palavra no texto. Ou talvez O jansenismo e o Machado, porque o autor não faz nenhum esforço para distinguir o que há de superficial e postiço no "jansenismo" de Pascal e, ao contrário, confunde sistematicamente as teorias de Port-Royal e as expansões do autor das Pensées. "Só há um Pascal - diznos ele - do polemista ao apologista, do filósofo moralista ao escritor, das Provinciales aos [sic] Pensées. E este Pascal transpira a doutrina jansenista, e toda a sua obra tem um tom jansenista" (COUTINHO, 1940, p. 113).

Essa estranha capacidade de indistinção, de imprecisão, paradoxalmente unida a um dogmatismo sem freios, parece ser o

${ }^{4} \mathrm{Na}$ primeira (HOLANDA, 1944) e na segunda (HOLANDA, 1978) edições de Cobra de vidro, lê-se aqui: "pela suposta extensão". 
característico supremo do sr. Afrânio Coutinho neste livro. E também, se não me engano, o seu vício capital, a base suspeita de todas as suas argumentações.

Não são em verdade erros de julgamento o que tanto desconsola em seu estudo como verdades absurdamente exageradas, ao ponto de se transformarem em falsificações. Ninguém ousa afirmar que Machado não tivesse lido muito Pascal, ou que o fizesse por distração. Seu próprio testemunho, dado em carta a Joaquim Nabuco, serve para indicar que a influência pode ter existido em grau apreciável. O erro está em acreditá-la tão envolvente e tão despótica como procura imaginar o sr. Afrânio Coutinho. Um estudo atento dos dois autores só pode levar a descobrir sob as semelhanças superficiais e epidérmicas a diferença profunda, vital, que na realidade os separa. Para pôr em relevo essa diferença seria o bastante, talvez, assinalar que Machado não era uma natureza religiosa como Pascal, que ele não procurava Deus.

Não é necessário acrescentar que todo o pensamento pascaliano é radicalmente coerente com essa natureza religiosa, com a fé convulsiva no Cristo, a crença profunda em Deus, no Deus sensível ao coração. E não é possível isolar o pensamento de Pascal de sua religião, sem falsear uma e outra coisa.

Comparado ao de Pascal, o mundo de Machado de Assis é um mundo sem começo, um mundo sem Paraíso. De onde uma insensibilidade incurável a todas as explicações que baseiem no pecado e na queda a ordem em que foram postas as coisas no mundo. Seu amoralismo tem raízes nessa insensibilidade fundamental. A lei moral nasce de uma demagogia caprichosa e insípida, boa para confortar a vaidade humana. Nossos atos não têm fim determinado e o espetáculo que oferece a agitação dos homens dá a mesma sensação que dão os discursos de um doido.

De onde também esse fato, que para a interpretação da obra de Machado de Assis tem suma importância: seu mundo não conhece a tragédia. Ou melhor, o trágico nele se dissolve no absurdo e o ridículo tem gosto amargo.

O ponto para onde convergem, principalmente, as similitudes entre Machado e Pascal, o lugar geométrico do confronto, é na opinião do sr. Afrânio Coutinho o "ódio à vida", o pessimismo frenético de ambos.

Existe realmente esse ódio à vida em Pascal? Parece-me que aceitar tão singelamente tal impressão é renunciar a compreender o essencial do pensamento pascaliano. A verdade é que a vida para ele não é inteligível sem o sacrifício e o sofrimento, que santificam o coração. Como Jesus ressurgiu 
dos mortos, assim também a alma deve renascer do pecado com o socorro da graça. A vida e a natureza não existem sem a presença de Deus, de um Deus escondido - Deus absconditus - que é preciso procurar com fervor. A vida nos impõe sofrimentos, mas não é odiosa por isso, uma vez que os sofrimentos constituem para o homem o caminho necessário da felicidade perfeita. "N'appelons mal que ce qui rend la victime de Dieu victime du diable... Tout est doux en J. C., jusqu'à la mort, et c'est pourquoi il a souffert et il est mort pour sanctifier la mort et les souffrances". ${ }^{5}$

Diante da obra de Machado de Assis essa mesma impressão de "ódio à vida" chega a ser verdadeira obsessão, revelada a cada momento pelo autor. "Ódio radical da vida..." (COUTINHO, 1940, p. 22). "Odiando a vida ele foi um grande recriador de vida" (COUTINHO, 1940, p. 23). "A humanidade que ele odeia" (COUTINHO, 1940, p. 162). "Ódio intenso da humanidade, ódio da vida, ódio jansenista" (COUTINHO, 1940, p. 163). "Em resumo pode-se dizer que Machado recebeu de Pascal o profundo pessimismo sobre a natureza humana, ou por outras palavras, o ódio radical da vida e dos homens" (COUTINHO, 1940, p. 142). Em cinco páginas (COUTINHO, 1940, p. 162 a 167) aparecem seis vezes repetidas as palavras sinistras: "ódio à vida", simplificação excessiva e traidora, que o exame da obra de Machado não autoriza a endossar. ${ }^{6}$ No simples ódio há uma ausência de complexidade e de nuances, uma limpidez, que dificilmente poderia explicar qualquer reação de Machado de Assis diante da vida. Os trechos onde ele parece exprimir mais veementemente os mesmos sentimentos que o sr. Afrânio Coutinho traduziu mal por "ódio à vida" ensinam justamente o contrário dessa simplificação. Em "Viver!" o verdadeiro centro, o ponto nuclear da história está não nas queixas de Ahasverus, mas sim nas suas palavras derradeiras, e também no diálogo das águias:

- Ai, ai, ai deste último homem, está morrendo e ainda sonha com a vida.

- Nem ele a odiou tanto, senão porque a amava muito.

E no delírio de Brás Cubas é o mesmo sentimento aí expresso que domina e orienta a narração inteira:

\footnotetext{
${ }^{5}$ Em O espírito e a letra, coletânea de textos críticos de Sérgio Buarque de Holanda organizada por Antonio Arnoni Prado, uma nota do organizador esclarece que a citação é de "Les mystères de Jesus", parte das Pensées de Pascal (PASCAL, 1936, p. 1059).

${ }^{6} \mathrm{Na}$ primeira (HOLANDA, 1944) e na segunda (HOLANDA, 1978) edições de Cobra de vidro, lê-se aqui: "'ódio à vida'. [parágrafo] Ainda aqui há pelo menos uma simplificação excessiva e traidora, que o exame da obra de Machado não autoriza endossar. No simples ódio..."
} 
- Viver somente, não te peço mais nada. Quem me pôs no coração este amor da vida, senão tu? e, se eu amo a vida, por que te hás de golpear a ti mesma, matando-me?

O "ódio à vida" explicaria, segundo o sr. Afrânio Coutinho, o empenho de Machado em desmoralizar os bons sentimentos. "É, portanto, uma intenção geral em Machado - diz-nos expressamente - a desmoralização dos bons sentimentos, todos eles, como lhe ensina Pascal, vãos e mentirosos, simples capa de hipocrisia sobre a realidade egoística" (COUTINHO, 1940, p. 159-160). Até onde é exato semelhante conceito expresso nesses termos cabais? E ainda admitindo que os bons sentimentos são deliberadamente negados pelo romancista, até onde é lícito admitir que ele só enxergou maldade no mundo? O que parece certo é que a maldade, os maus sentimentos, são a seu ver tão inexistentes, ou melhor, tão absurdos, como a bondade. E tão ridículos, se quiserem.

Essa atitude tem um nome bem expressivo, um nome que parece não agradar o investigador da filosofia machadiana. Chama-se ceticismo. Creio que o sr. Afrânio Coutinho tem razão ao dizer que a atitude cética não explica toda a obra de Machado. E quero crer também que é necessário distingui-la da que exprime esse outro mestre do ceticismo, Anatole France. Machado de Assis pode desprezar os homens, como France, mas não os despreza com ternura, antes com certo amargor. Todos os seus escritos estão impregnados desse arrepio acre, desse "Schaudern" em que Goethe via o melhor do homem. ${ }^{7}$ É que em verdade Machado de Assis não parece deliciarse profundamente em sua própria descrença. E talvez sentisse como uma inferioridade a inaptidão para ver os homens de outra forma, para julgá-los dignos de amor. Assim, sob as aparências de uma zombaria constante, esconde um sentimento de deficiência. O "humour" é expressão adequada desse disfarce.

Na ideia de um mundo absurdo - não trágico, mas absurdo - somada a esse sentimento de penúria encoberto pela ironia, é que, segundo me parece, devem ser procuradas as origens do "humour" de Machado de Assis. ${ }^{8,9} \mathrm{O}$ sr. Afrânio Coutinho engana-se, e desta vez profundamente, ao explicar o humorismo, mostrando que não se trata de simples expressão literária do

\footnotetext{
${ }^{7} \mathrm{Na}$ segunda edição (HOLANDA, 1978) de Cobra de vidro, não consta toda esta frase.

${ }^{8} \mathrm{Na}$ primeira (HOLANDA, 1944) e na segunda (HOLANDA, 1978) edições de Cobra de vidro, lê-se aqui: "devem ser procuradas as origens do "humour" de Machado de Assis e também as fontes de sua filosofia."

${ }^{9}$ Na primeira (HOLANDA, 1944) e na segunda (HOLANDA, 1978) edições de Cobra de vidro, o artigo se encerra aqui.
} 
ceticismo. Quando diz que "há humoristas tristes e humoristas vibrantes, há os alegres e os doloridos, há os risonhos e os céticos, os ingênuos e os amargos, os pessimistas e os esperançosos, os desencantados e os líricos, os satíricos e os revolucionários" (COUTINHO, 1940, p. 32). Com mais essa indistinção o autor deixa escapar o sentido essencial da palavra "humour". Nesse sentido o "humour" - "lágrima que ri" - é sempre triste, dolorido, amargo, desencantado... E não só em Machado de Assis como em todo verdadeiro humorista.

Diante dos aspectos que procurei apontar no livro do sr. Afrânio Coutinho, da fragilidade tão patente dos seus argumentos em favor de uma tese artificial e forçada, não sei esconder a impressão de que o autor não chegou a formar uma convicção bem definida a respeito do que sustenta. Suas frases sucedem-se como um pensamento ainda nebuloso, mal descansado, à procura de um ponto onde se arrime e ganhe segurança. $\mathrm{O}$ resultado é que se deixa a última página com uma intensa decepção. Tanto mais intensa quanto essa insegurança dogmática, ao que me parece, não costuma ser característica do sr. Afrânio Coutinho.

\section{Referências}

COUTINHO, Afrânio. A filosofia de Machado de Assis. Rio de Janeiro: Casa Editora Vecchi, 1940.

HOLANDA, Sérgio Buarque de. A filosofia de Machado de Assis. Diário de Notícias, Rio de Janeiro, 22 dez. 1940, p. 17 e 20. . A filosofia de Machado de Assis. In: Cobra de vidro. Rio de Janeiro: Editora Martins, 1944. p. 44-51.

A filosofia de Machado de Assis. In: Cobra de vidro. São Paulo: Perspectiva, 1978. p. 53-58.

A filosofia de Machado de Assis. In: O espírito e a letra. Organização de Antonio Arnoni Prado. São Paulo: Companhia das Letras, 1996. v. 1, p. 305312.

MONTEIRO, Pedro Meira. Machado de Assis: uma flor desajeitada no jardim modernista. In: GUIMARÃES, Hélio de Seixas; SENNA, Marta de (Orgs.). Machado de Assis: permanências. Rio de Janeiro: Edições Casa de Rui Barbosa; 7Letras, 2018. p. 253-270.

PASCAL, Blaise. L'Euvre de Pascal. Estabelecimento de texto e notas de Jacques Chevalier. Paris: Éditions de la Nouvelle Revue Française, 1936. 